OPEN ACCESS

Edited by: Federico Biscetti,

Catholic University of the Sacred

Heart, Italy

Reviewed by:

Verena Peters,

Heidelberg University Hospital,

Germany

Antonio Bianchi,

Agostino Gemelli University Polyclinic,

Italy

*Correspondence:

Sheng-Lin Liu

2874151850@qq.com

Zhong-Ze Fang

fangzhongze@tmu.edu.cn

${ }^{\dagger}$ These authors have contributed equally to this work

Specialty section:

This article was submitted to

Clinical Diabetes,

a section of the journal

Frontiers in Endocrinology

Received: 20 October 2020

Accepted: 14 December 2020

Published: 09 February 2021

Citation:

Gao X, Hou R, Li X, Qiu X-H, Luo H-H,

Liu S-L and Fang Z-Z (2021) The

Association Between Leucine

and Diabetic Nephropathy

in Different Gender: A Cross-

Sectional Study in Chinese

Patients With Type 2 Diabetes.

Front. Endocrinol. 11:619422.

doi: 10.3389/fendo.2020.619422

\section{The Association Between Leucine and Diabetic Nephropathy in Different Gender: A Cross-Sectional Study in Chinese Patients With Type 2 Diabetes}

\author{
Xiaoqian Gao ${ }^{1 \dagger}$, Ruiqin $\mathrm{Hou}^{2 \dagger}$, Xin $\mathrm{Li}^{1}$, Xing-Hua Qiu ${ }^{3}$, Hui-Huan Luo ${ }^{1}$, Sheng-Lin Liu ${ }^{4 *}$ \\ and Zhong-Ze Fang ${ }^{1,5 *}$ \\ ${ }^{1}$ Department of Toxicology and Sanitary Chemistry, School of Public Health, Tianjin Medical University, Tianjin, China, \\ 2 Department of Blood Transfusion, Peking University People's Hospital, Beijing, China, ${ }^{3}$ State Key Joint Laboratory of \\ Environmental Simulation and Pollution Control, College of Environmental Sciences and Engineering, Peking University, \\ Beijing, China, ${ }^{4}$ Department of Laboratory Center of Tianjin Xiqing Hospital, Tianjin, China, ${ }^{5}$ Tianjin Key Laboratory of \\ Environment, Nutrition and Public Health, Tianiin, China
}

Objective: This study aimed to evaluate how leucine are associated with diabetic nephropathy (DN) in type 2 diabetes (T2D) patients and the gender difference of this association.

Methods: We retrieved 1,031 consecutive patients with T2D who meet the inclusion and exclusion criteria from the same tertiary care center and extracted clinical information from electronic medical record. Plasma leucine was measured by liquid chromatography-mass spectrometer. Restricted cubic spline (RCS) was conducted to examine potential nonlinear relationship between leucine and the risk of DN. Logistic regression was used to obtain odds ratio $(\mathrm{OR})$ and confidence interval $(\mathrm{Cl})$. Additive interaction was used to estimate the interaction effect between leucine and gender for DN.

Results: We found there was a negative correlation between leucine and the risk of DN. After stratifying all patients by gender, this relationship only remained significant in women (OR:0.57, Cl:0.41-0.79).

Conclusions: In conclusion, T2D patients with high levels of leucine have a lower risk of developing DN in female.

Keywords: leucine, diabetic nephropathy, metabolism, type 2 diabetes, gender

\section{INTRODUCTION}

Diabetic nephropathy (DN), one of the common complications of diabetes, greatly increases mortality and medical expenses in type 2 diabetes (T2D) patients $(1,2)$. DN increased enormous societal burden, as it also amplifies the risk of other diabetes complications including cardiovascular disease, heart failure, infections (3-7). Since DN is a kind of progressive disease, it is important to 
search for new approaches that can effectively forecast and prevent the onset of DN. However, noninvasive available markers for accurate prediction and diagnoses of $\mathrm{DN}$ in diabetic patients are lacking now (8). It is worth noting that many studies have found the burden of diabetes is different in different genders $(9,10)$. For example, women have higher mortality rate for diabetes-related deaths, including DN (9). One may speculate that there is maybe something different in pathology and predictors of DN between men and women.

The development of new technologies allows the highthroughput profiling of metabolic status from a blood specimen (metabolomics). More and more researches focused on exploring whether metabolite profiles affect the onset and development of DN via combining epidemiology and metabolomics (11-14).

Insufficient insulin secretion, one of the risk factor of DN, was found to be closely associated with plasma amino acids level (15). Different from other amino acids, leucine, one of branched-chain amino acids (BCAAs), is catabolized in skeletal muscle which is important organ for the regulation of blood glucoses $(16,17)$. In addition to the metabolic roles, leucine was reported in many studies as the regulator of the mechanistic target of rapamycin (mTOR) pathway which could affect insulin secretion (18). In animal tests, leucine was found attenuate DN progression (19, 20). Although physiological investigations suggested great insight into mechanisms, yet they do not conclusively illustrate that such mechanisms work at the population level in humans. In fact, there was only some population studies expounding the relationship between leucine and diabetes, but it is still a lack of population evidence about leucine and the risk of DN (21).

In this study, we established a cross-sectional study in a Chinese population, and aimed to 1) evaluate association between plasm leucine and risk of $\mathrm{DN} ; 2$ ) examine whether this association will change in different gender.

\section{MATERIALS AND METHODS}

\section{Study Method and Population}

We retrieved electronic medical records with available metabolite data from the First Affiliated Hospital of Liaoning Medical University (FAHLMU) in Jinzhou, Liaoning Province, China. The inclusion criteria were: diagnosed as T2D or treated with antidiabetic drugs. Exclusion criteria were: 1) ages under 18 years old; 2) lacked height, weight and blood pressure. A total of 1898 T2D patients were preliminarily enrolled into this study. According to the exclusion criteria, 866 patients were excluded as under 18 years and 1 was excluded as lacked height, weight and blood pressure. Finally, a total of 1031 research subjects were included the present study. Among them, $188 \mathrm{DN}$ patients were diagnosed. The diagnosis and classification of type 2 diabetes mellitus in the present study were based on the standard published by World Health Organization(WHO) or treated with antidiabetic drugs (22). The diagnostic criteria for diabetic nephropathy was based on the standards of care for type 2 diabetes (23).
The Ethics Committee for Clinical Research of FAHLMU approved the ethics of the study, and informed consent was waivered due to the retrospective nature of the study, which is consistent with the Declaration of Helsinki.

\section{Data Collection and Clinical Definitions}

The data retrieved from the electronic medical records for both groups contained demographic and anthropometric information, as well as current clinical factors, medications and complications of diabetes. Demographic included gender, current status of smoking and alcohol consumption. Anthropometric measurements yielded information included height, weight, systolic blood pressure (SBP) and diastolic blood pressure (DBP). Clinical parameters contained glycosylated hemoglobin((HbAlc), triglyceride (TG), high-density lipoprotein cholesterol (HDL-C), low-density lipoprotein cholesterol (LDL-C), urinary creatinine (UA), serum creatinine (SCR). Details of medication use were documented, including oral anti-diabetic drugs, insulin, and lipid lowering drugs, statins. Duration of diabetes and diabetic nephropathy were recorded.

In hospitals, anthropometric indices were measured by using standardized procedures. Participants were allowed to wear light clothes and no shoes. Height and weight were measured to the nearest $0.5 \mathrm{~cm}$ and $0.1 \mathrm{~kg}$ respectively. Blood pressure was measured behind the right arm of an adult cuff using a standard mercury sphygmomanometer and post-measurement at an appropriate size, after a $10 \mathrm{~min}$ rest in a sitting position. Age was calculated from the date of birth to the date of hospitalization or medical examination, and was calculated in years. The body mass index (BMI) was calculated as the ratio of weight $(\mathrm{kg})$ to squared height(meters) classifying overweight and obesity according to the criteria recommended by the National Health Commission in China (24). DN was defined as persistent albuminuria, progressive reduction in glomerular filtration rate (GFR) and hypertension judged by clinicians.

\section{Laboratory Assay}

Dried blood spots were used in the assay of metabolomics, which were prepared from capillary whole blood through 8 -h fasting. We measured the metabolites by direct infusion mass spectrometry technology equipped with the AB Sciex 4000 QTrap system (AB Sciex, Framingham, MA, USA). Highpurity water and acetonitrile were purchased from Thermo Fisher (Waltham, MA, USA), and utilized as diluting agent and mobile phase. 1-Butanol and acetyl chloride were obtained from Sigma-Aldrich (St Louis, MO, USA). Isotope-labeled internal standard samples of amino acids (NSK-A) were purchased from Cambridge Isotope Labo-ratories (Tewksbury, MA, USA), while standard samples of the leucine were purchased from Chrom Systems (Grafelfing, Germany). In brief, $8.5 \mathrm{~mL}$ of venous blood was drawn from each participant at $08: 00$ to $09.30 \mathrm{~h}$ in the morning after 8 -h fasting. Laboratory tests were carried out at a special diagnostic laboratory. The level of lipid profiles was analyzed by an automatic biochemistry analyzer (Hitachi 7150, Tokyo, Japan). We also assayed the level of HDL-C and LDL-C by the selective solubilization 
method (12) (Determiner L-HDL, LDL test kit; Kyowa Medex, Tokyo, Japan).

\section{Statistical Analysis}

Data with the normal distribution was represented by the mean \pm standard deviation (SD), or use the median (interquartile range). Categorical variable was in numbers (percentage). Whether there was a difference between DN group and non-DN group were tested separately in male and female. The continuous variable was judged by student's t-test or separate variance estimation ttest or Wilcox-W test when appropriate; Categorical variable was analyzed by chi-square test.

Binary logistic regression model was established to obtain the odds ratio (OR) and their 95\% confidence intervals (CI). Traditional risk factors for type 2 diabetes patients with DN were adjusted using a structured adjustment scheme. We obtained unadjusted OR values and the OR after adjusted age, gender, BMI $(<18.5,18.5-$ $\left.24.0,24.0-28.0,>28.0 \mathrm{~kg} / \mathrm{m}^{2}\right)$, duration of diabetes, smoking, drinking, SBP, DBP, TG, LDL-C, HDL-C, HbAlc, UA, SCR, insulin, statins. Restricted cubic splines curve (RCS) is a smoothing curve that can provide more intuitive relationship curve. We chose 4 knots in RCS (25). We have used it to obtain cutoffs for metabolites related to the risk of developing diabetes (26). We selected a cut-off point by visual checking of the curve where the odds of DN changed.
We repeated logistic regression analysis in males and females respectively to obtain OR values. Additive interaction analysis was used to verify the relationship between gender (male or female) and leucine (in 2 groups by RCS cutoff) for DN. We calculated the relative excess risk due to interaction (RERI), attributable proportion due to interaction (AP) and synergy index $(S)$ to estimate additive interactions (27). RERI $>0, A P>0$ or $\mathrm{S}>1$ indicates a significant additive interaction (27). To avoid the bias caused by non-incident DN. We exclude the patients who with duration of $\mathrm{DN}>2$ years to check the changes of the effect sizes of leucine for risk of DN.

A $p<0.05$ was considered as statistically significant. All analyses were performed using $\mathrm{R}$ version 3.6 and SAS version 9.4 (Institute Inc., Cary, North Carolina, USA).

\section{RESULT}

\section{Description of Study Subjects}

The mean age and BMI of 1031 participants were 57.2 years (SD:13.8) and $25.3 \mathrm{~kg} / \mathrm{m}^{2}$ (SD:3.9). Of them, $46.8 \%$ were female. There was a total of 188 patients with $\mathrm{DN}$ and 92 of them are women. Table 1 summarized the selected characteristics of DN and controls by sex. In women, cases tended to be older, had

TABLE 1 | Clinical and biochemical characteristics of participants according to the occurrence of diabetic nephropathy

\begin{tabular}{|c|c|c|c|c|c|c|}
\hline \multirow[t]{3}{*}{ Variables } & \multicolumn{2}{|c|}{ Women } & \multirow[t]{3}{*}{$p^{a}$} & \multicolumn{2}{|c|}{ Men } & \multirow[t]{3}{*}{$p^{a}$} \\
\hline & Non-DN (391) & DN (92) & & Non-DN (452) & DN (96) & \\
\hline & Mean/number (SD or \%) & Mean/number (SD or \%) & & Mean/number (SD or \%) & Mean/number (SD or \%) & \\
\hline Age (years) & $59.16 \pm 12.81$ & $60.54 \pm 9.8$ & $<0.001$ & $54.75 \pm 14.81$ & $57.72 \pm 14.33$ & 0.074 \\
\hline Weight (kg) & $63.64 \pm 10.56$ & $67.11 \pm 13.21$ & 0.007 & $75.72 \pm 12.79$ & $75.43 \pm 11.04$ & 0.840 \\
\hline Height (cm) & $160.00(156.00,163.00)$ & $160.00(158.00,165.00)$ & 0.235 & $172.00(170.00,175.00)$ & $172.00(170.00,175.00)$ & 0.616 \\
\hline BMl $\left(\mathrm{kg} / \mathrm{m}^{2}\right)$ & $24.83 \pm 3.83$ & $25.87 \pm 4.36$ & 0.024 & $25.53 \pm 3.83$ & $25.54 \pm 3.41$ & 0.977 \\
\hline$B M \mid<18.5$ & $70(17.9 \%)$ & 24(26.1\%) & & 104(23.0\%) & 23(24.0\%) & \\
\hline $\mathrm{BMI} \geq 18.5$ and $<24.0$ & $150(38.4 \%)$ & $32(34.8 \%)$ & & $211(46.7 \%)$ & $37(38.5 \%)$ & \\
\hline $\mathrm{BMI} \geq 24.0$ and $<28.0$ & $162(41.4 \%)$ & $34(37.0 \%)$ & & $122(27.0 \%)$ & $35(36.5 \%)$ & \\
\hline $\mathrm{BMI} \geq 28.0$ & $9(2.3 \%)$ & $2(2.2 \%)$ & & 15(3.3\%) & $1(1.0 \%)$ & \\
\hline Smokingyes & 25 (6.4\%) & $8(8.7 \%)$ & 0.577 & $243(53.8 \%)$ & $55(57.3 \%)$ & 0.604 \\
\hline Drinkingyes & $13(3.3 \%)$ & $2(2.2 \%)$ & 0.811 & $221(48.9 \%)$ & $54(56.2 \%)$ & 0.231 \\
\hline Duration of diabetes (years) & $6.97 \pm 7.44$ & $8.93 \pm 7.71$ & 0.024 & $3.00(0.00,10.00)$ & $10.00(2.75,14.25)$ & $<0.001$ \\
\hline $\mathrm{SBP}(\mathrm{mmHg})$ & $140.00(122.00,155.00)$ & $149.50(129.50,174.00)$ & 0.001 & $138.71 \pm 22.46$ & $142.1 \pm 22.42$ & 0.179 \\
\hline $\mathrm{DBP}(\mathrm{mmHg})$ & $80.79 \pm 13.52$ & $83.23 \pm 12.59$ & 0.116 & $83.79 \pm 13.3$ & $82.25 \pm 14.82$ & 0.312 \\
\hline $\mathrm{HbA} 1 \mathrm{c}(\%)$ & $7.53 \pm 3.22$ & $8.64 \pm 2.68$ & 0.002 & $7.66 \pm 3.07$ & $8.24 \pm 3.11$ & 0.096 \\
\hline Triglyceride (mmol/L) & $1.22(0.82,2.08)$ & $1.52(1.02,2.31)$ & 0.089 & $1.22(0.82,2.00)$ & $1.31(0.89,1.97)$ & 0.561 \\
\hline HDL-C (mmol/L) & $0.90 \pm 0.45$ & $1.07 \pm 0.52$ & 0.001 & $0.84(0.45,1.06)$ & $0.85(0.50,1.07)$ & 0.265 \\
\hline LDL-C (mmol/L) & $2.42 \pm 1.24$ & $2.79 \pm 1.31$ & 0.013 & $2.25(1.13,2.95)$ & $2.42(1.27,3.04)$ & 0.505 \\
\hline $\mathrm{SCR}(\mu \mathrm{mol} / \mathrm{L})$ & $53.51(43.41,70.95)$ & $57.55(45.59,119.00)$ & 0.028 & $68.72(58.00,91.10)$ & $87.78(64.41,314.17)$ & $<0.001$ \\
\hline UA $(\mu \mathrm{mol} / \mathrm{L})$ & $307.00(238.00,445.50)$ & $340.60(264.25,532.35)$ & 0.073 & $345.00(274.75,499.00)$ & $391.50(326.00,778.00)$ & 0.004 \\
\hline Leucine ( $\mu \mathrm{mol} / \mathrm{L})$ & $124.87 \pm 43.17$ & $112.69 \pm 31.61$ & $<0.001$ & $143.18 \pm 49.85$ & $137.24 \pm 46.56$ & $<0.001$ \\
\hline$<175 \mu \mathrm{mol} / \mathrm{L}$ & 349(79.9\%) & 42(93.33\%) & & 352(77.87\%) & 100(22.12\%) & \\
\hline \multicolumn{7}{|l|}{ Diabetic medications } \\
\hline Acarbose & 129 (33.0\%) & $43(46.7 \%)$ & 0.018 & 150 (33.2\%) & $42(43.8 \%)$ & 0.064 \\
\hline Metformin & $131(33.5 \%)$ & $41(44.6 \%)$ & 0.061 & 155 (34.3\%) & 31 (32.3\%) & 0.797 \\
\hline Insulin & 275 (70.3\%) & 85 (92.4\%) & $<0.001$ & 321 (71.0\%) & 90 (93.8\%) & $<0.001$ \\
\hline Statins & 131 (33.5\%) & 45 (48.9\%) & 0.008 & 152 (33.6\%) & 41 (42.7\%) & 0.116 \\
\hline
\end{tabular}

Data are mean (standard deviation), median (interquartile range) or $n$ (\%). BMI, body mass index. SBP, systolic blood pressure. DBP, diastolic blood pressure. HbA1C, glycated hemoglobin. HDL-C, high-density lipoprotein cholesterol. LDL-C, low-density lipoprotein cholesterol. UA, uric acid. SCR, serum creatinine.

${ }^{a}$ Based on the t-test, Wilcoxon rank-sum test or $\chi^{2}$ test as appropriate. 
higher BMI and longer duration of diabetes, higher SBP, HbA1c, HDL-C, LDL-C, and SCR, and were less likely to use insulin and statins than patients without DN. In men, patients with DN had longer duration of T2D, higher SCR, UA and were less likely to use insulin than controls.

\section{The Relationship Between Diabetic Nephropathy and Leucine}

The slope of RCS curve has a process from small to large and then small, which reaches its maximum at about $175 \mu \mathrm{mol} / \mathrm{L}$. Among all patients, leucine level of $84.8 \%$ patient were below $175 \mu \mathrm{mol} / \mathrm{L}$ (Figure 1).

In univariable regression, leucine was inversely associated with the risk of DN (OR: 0.8, 95\% CI:0.67, 0.95). After further adjustment for traditional risk factors, the negative association was strengthened in multivariable analysis (OR:0.76, 95\%CI: 0.62, 0.92) (Table 2).

\section{Interaction Between Leucine and Gender}

Leucine was negative associated with the risk of $\mathrm{DN}$ in diabetes patients in the female population (OR: $0.51,95 \% \mathrm{CI}: 0.41,0.79$ ) while the relationship was not significant in male (Table 3). In female the risk of DN was decrease rapidly until around $175 \mu \mathrm{mol} / \mathrm{L}$ of leucine and then started to relatively flat afterwards. In male, the association between BMI and

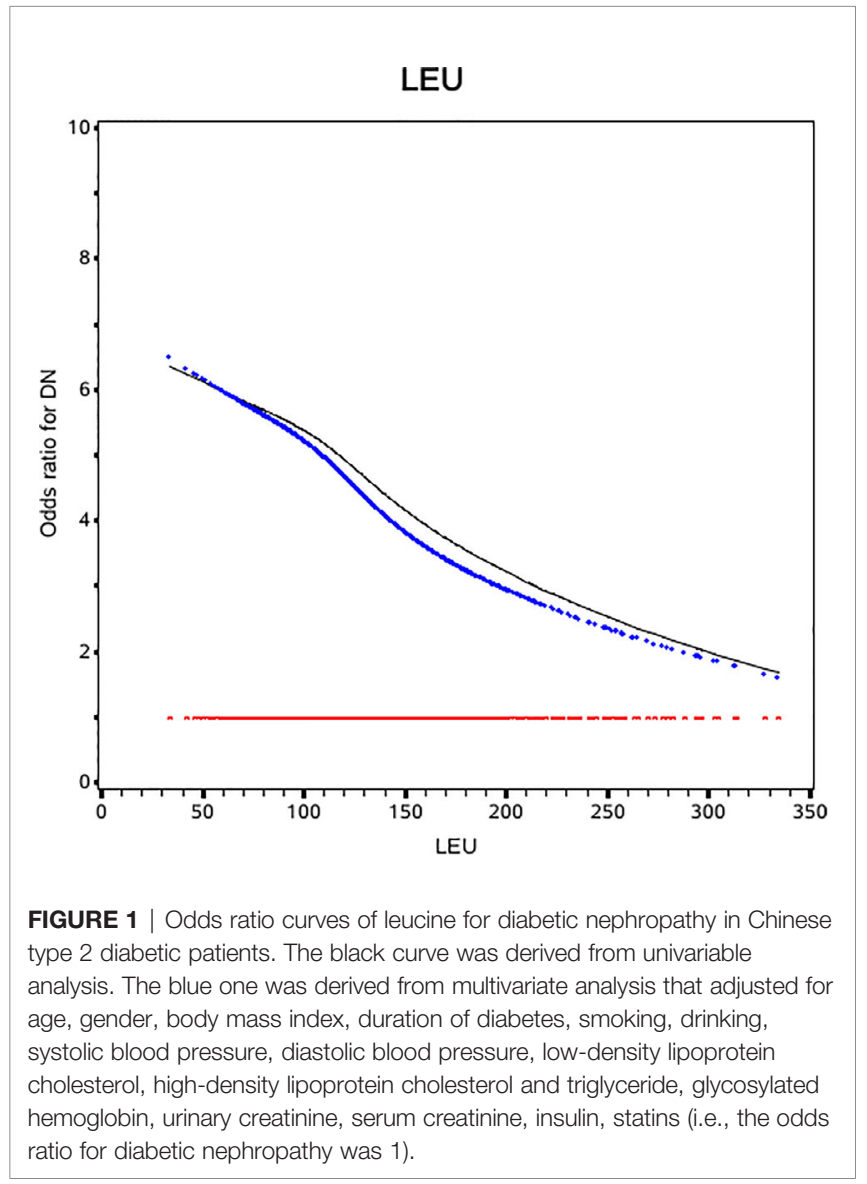

TABLE 2 | Odds ratio of leucine for the risk of diabetic nephropathy.

\begin{tabular}{|c|c|c|}
\hline & OR (95\%Cl) & $p$ \\
\hline \multicolumn{3}{|l|}{ Univariable model } \\
\hline $\begin{array}{l}\text { Leucine, per } \mu \mathrm{mol} / \mathrm{L} \\
<175 \mu \mathrm{mol} / \mathrm{L}\end{array}$ & $\begin{array}{c}0.8(0.67,0.95) \\
\text { reference }\end{array}$ & 0.012 \\
\hline$\geq 175 \mu \mathrm{mol} / \mathrm{L}$ & $0.59(0.36,0.97)$ & 0.036 \\
\hline \multicolumn{3}{|l|}{ Multivariable model1 } \\
\hline $\begin{array}{l}\text { Leucine, per } \mu \mathrm{mol} / \mathrm{L} \\
<175 \mu \mathrm{mol} / \mathrm{L}\end{array}$ & $\begin{array}{l}0.8(0.67,0.96) \\
\text { reference }\end{array}$ & 0.016 \\
\hline$\geq 175 \mu \mathrm{mol} / \mathrm{L}$ & $0.61(0.37,1.01)$ & 0.045 \\
\hline \multicolumn{3}{|l|}{ Multivariable model2 } \\
\hline $\begin{array}{l}\text { Leucine, per } \mu \mathrm{mol} / \mathrm{L} \\
<175 \mu \mathrm{mol} / \mathrm{L}\end{array}$ & $\begin{array}{c}0.76(0.63,0.92) \\
\text { reference }\end{array}$ & 0.006 \\
\hline$\geq 175 \mu \mathrm{mol} / \mathrm{L}$ & $0.56(0.33,0.94)$ & 0.044 \\
\hline \multicolumn{3}{|l|}{ Multivariable model3 } \\
\hline $\begin{array}{l}\text { Leucine, per } \mu \mathrm{mol} / \mathrm{L} \\
<175 \mu \mathrm{mol} / \mathrm{L}\end{array}$ & $\begin{array}{l}0.76(0.62,0.92) \\
\text { reference }\end{array}$ & 0.006 \\
\hline$\geq 175 \mu \mathrm{mol} / \mathrm{L}$ & $0.58(0.34,0.99)$ & 0.038 \\
\hline
\end{tabular}

Multivariable Model 1 was adjusted for age, gender, body mass index, duration of diabetes, smoking, drinking.

Multivariable Model 2 was adjusted for variables in Model 1 and concentrations of systolic blood pressure, diastolic blood pressure, triglyceride, low-density lipoprotein cholesterol, high-density lipoprotein cholesterol, glycosylated hemoglobin.

Multivariable Model 3 was adjusted for variables in Model 2 and concentrations of uric acid, serum creatinine, use of insulin, use of statins.

TABLE 3 | Odds ratio of leucine for the risk of diabetic nephropathy in different gender.

\begin{tabular}{|c|c|c|c|c|}
\hline & \multicolumn{2}{|c|}{ Female $(n=483)$} & \multicolumn{2}{|c|}{ Male $(n=548)$} \\
\hline & OR(95\%Cl) & $p$ & OR(95\%Cl) & $p$ \\
\hline \multicolumn{5}{|l|}{ Univariable model } \\
\hline $\begin{array}{l}\text { Leucine per } \mu \mathrm{mol} / \mathrm{L} \\
<175 \mu \mathrm{mol} / \mathrm{L}\end{array}$ & $\begin{array}{l}0.71(0.55,0.93) \\
\text { reference }\end{array}$ & 0.008 & $\begin{array}{l}0.88(0.7,1.11) \\
\text { reference }\end{array}$ & 0.274 \\
\hline$\geq 175 \mu \mathrm{mol} / \mathrm{L}$ & $0.28(0.08,0.92)$ & 0.037 & $0.76(0.43,0.34)$ & 0.329 \\
\hline \multicolumn{5}{|l|}{ Multivariable model1 } \\
\hline $\begin{array}{l}\text { Leucine, per } \mu \mathrm{mol} / \mathrm{L} \\
<175 \mu \mathrm{mol} / \mathrm{L}\end{array}$ & $\begin{array}{l}0.7(0.53,0.91) \\
\text { reference }\end{array}$ & 0.009 & $\begin{array}{l}0.90(0.71,1.14) \\
\text { reference }\end{array}$ & 0.380 \\
\hline$\geq 175 \mu \mathrm{mol} / \mathrm{L}$ & $0.29(0.09,0.98)$ & 0.045 & $0.78(0.44,1.38)$ & 0.394 \\
\hline \multicolumn{5}{|l|}{ Multivariable model2 } \\
\hline $\begin{array}{l}\text { Leucine, per } \mu \mathrm{mol} / \mathrm{L} \\
<175 \mu \mathrm{mol} / \mathrm{L}\end{array}$ & $\begin{array}{l}0.59(0.43,0.81) \\
\text { reference }\end{array}$ & 0.001 & $\begin{array}{l}0.90(0.71,1.12) \\
\text { reference }\end{array}$ & 0.399 \\
\hline$\geq 175 \mu \mathrm{mol} / \mathrm{L}$ & $0.26(0.07,0.87)$ & 0.030 & $0.75(0.42,1.36)$ & 0.345 \\
\hline \multicolumn{5}{|l|}{ Multivariable model3 } \\
\hline $\begin{array}{l}\text { Leucine, per } \mu \mathrm{mol} / \mathrm{L} \\
<175 \mu \mathrm{mol} / \mathrm{L}\end{array}$ & $\begin{array}{l}0.57(0.41,0.79) \\
\text { reference }\end{array}$ & $<0.001$ & $\begin{array}{l}0.92(0.71,1.18) \\
\text { reference }\end{array}$ & 0.493 \\
\hline$\geq 175 \mu \mathrm{mol} / \mathrm{L}$ & $0.24(0.07,0.83)$ & 0.024 & $0.81(0.44,1.48)$ & 0.489 \\
\hline
\end{tabular}

Multivariable Model 1 was adjusted for age, body mass index, duration of diabetes, smoking, drinking.

Multivariable Model 2 was adjusted for variables in Model 1 and concentrations of systolic blood pressure, diastolic blood pressure, triglyceride, low-density lipoprotein cholesterol, high-density lipoprotein cholesterol, glycosylated hemoglobin.

Multivariable Model 3 was adjusted for variables in Model 2 and concentrations of uric acid, serum creatinine, use of insulin, use of statins.

mortality disappeared (Figure 2). Using 175 as a cutoff value of leucine, leucine $(<175$ or $\geq 175 \mu \mathrm{mol} / \mathrm{L}$ ) and gender (male or female) had a significant additive interaction for DN (AP: 0.90, 95\%CI: $0.18-1.62$; RERI: $0.60,95 \%$ CI: $0.08-1.12$; and S: 0.36 , $95 \%$ CI: $0.11-1.20)$. 
male

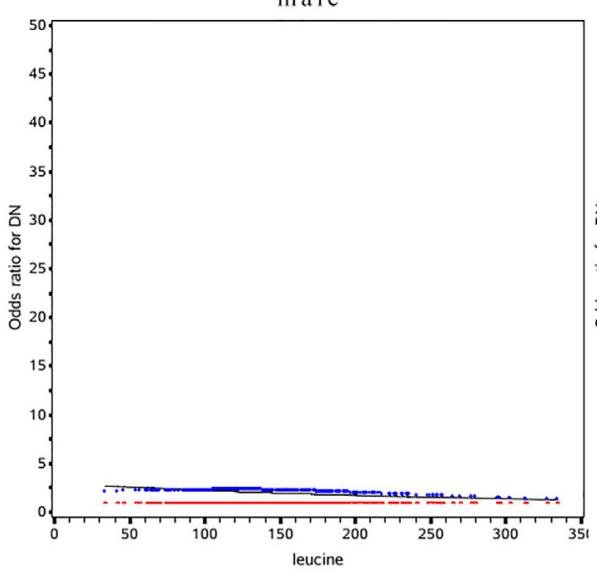

female

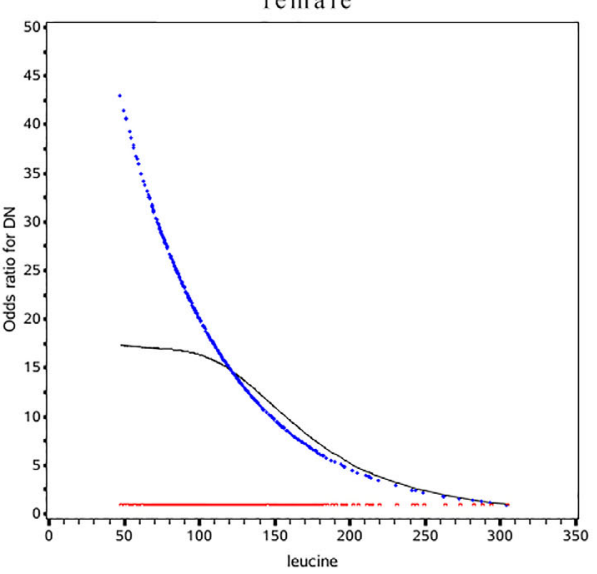

FIGURE 2 | Odds ratio curves of leucine for diabetic nephropathy in Chinese type 2 diabetic patients in different gender. The black curve was derived from univariable analysis, the blue one derived from multivariate analysis that adjusted for age, gender, body mass index, duration of diabetes, smoking, drinking, systolic blood pressure, diastolic blood pressure, low-density lipoprotein cholesterol, high-density lipoprotein cholesterol, triglyceride, glycosylated hemoglobin, urinary creatinine, serum creatinine, insulin, statins(i.e., the odds ratio for diabetic nephropathy was 1).

\section{Sensitivity Analysis}

After excluding 10 patients who had DN for more than 2 years, the effect size was larger. In the multivariable analysis, the OR value became $0.74(0.61,0.91)$, and the OR value in the female population changed to 0.56 (CI: $0.40,0.77)$.

\section{DISCUSSION}

So far, only a limited number of studies have reported the relationship between leucine and $\mathrm{DN}$, and more research focused on the relationship between leucine and diabetes or insulin resistance. For example, the classic Framingham's 12year cohort study showed leucine was relevant metabolites in developing diabetes and confirmed the result in the Malmo cohort (28). On the contrary, increased levels of leucine reduced the risk of diabetes in a healthy Japanese population with lower BMI (29). Newgard's research shows that BCAA contributes to development of obesity-associated insulin resistance, with no significant relationship in lean subjects $(15,30)$. Only a few population researches investigated the association between leucine and DN. The cross-sectional metabonomic studies was found that patients with $\mathrm{DN}$ or albuminuria have lower plasma leucine levels than those only with diabetes $(31,32)$. And in a case-cohort study, leucine was inversely associated with risk of mortality of vascular disease in individuals with type 2 diabetes (33). In the present study, we found that patients with DN was indeed more likely to have a lower leucine level. And low plasm leucine level was associated with high risk of $\mathrm{DN}$ in total subject diabetes patients. Furthermore, we found the relationship between leucine and DN was gender-related. Female with lower plasma leucine had more risk of DN than those who had higher, while in male, leucine did not show significant protective or hazardous effect. In fact, mechanism researches suggested that leucine could activate mTORC1 which control the protein then effect insulin secretion (18, 34-38). Interestingly, mTOR showed a higher expression in females, which explains the gender difference in the effect of leucine on insulin in animal experiments (39-41). Those are consistent with our research results.

Our finding had important clinical and research implications: 1) Discovery of the relationship between leucine and $D N$ will be helpful in diagnosis and disease prediction. Combine a lot of previous researches suggested leucine activates the mTORC1, we speculate that leucine may be a potential predictor of $\mathrm{DN} ; 2$ ) Previously, gender differences in the development of DN were identified. We further clarified the protective effect of leucine on $\mathrm{DN}$ only observed in women with diabetes. This observation partly proved that the activation of $\mathrm{mTOR}$ by leucine was gender different in the mechanism studies.

The present study has some limitations. Firstly, the crosssectional study can only prove the statistical association between plasma leucine and $\mathrm{DN}$, but not the exact causal relationship. Due to the lack of research in population, this study provides clues and direction to the further relevant study. Secondly, the levels of leucine are partly influenced by the dietary habits. Since we retrospectively retrieved the data from the hospital's electronic medical records, the information regarding the diet was not available for further investigation. In order to avoid the bias caused by dietary as much as possible, we used fasting samples and adjusted BMI, LDL-C, HDL-C, and triglyceride; Thirdly, our subjects were hospitalized with T2D, who may have more severe T2D and DN. Thus, caution must be taken when generalizing our findings to other populations; Finally, we did not collect the information of the stage of $\mathrm{DN}$ and there may be some changes in metabolism at different stages. We try to exclude patients with $\mathrm{DN}$ for more than 2 years in sensitivity analysis roughly estimate of disease stages. The results were still significant in the total study population and female population. 
Therefore, the report of this study may have a low estimate of the protective effect of leucine on risk of DN.

In conclusion, our study shows that leucine was inversely association with the risk of $\mathrm{DN}$ in total subjects and in women with T2D in Chinese. The present study further clarified that this inverse relation between leucine and risk of DN is only observed in women with diabetes, not men with diabetes. It may be a new direction for disease prevention and prediction. Further follow-up studies with stronger causality proving ability are needed to confirm this association in Chinese people and other populations.

\section{DATA AVAILABILITY STATEMENT}

The raw data supporting the conclusions of this article will be made available by the authors, without undue reservation.

\section{ETHICS STATEMENT}

The studies involving human participants were reviewed and approved by First Affiliated Hospital of Liaoning Medical University. Written informed consent for participation was not required for this study in accordance with the national legislation and the institutional requirements.

\section{REFERENCES}

1. Gross JL, De Azevedo MJ, Silveiro SP, Canani LH, Caramori ML, Zelmanovitz T. Diabetic nephropathy: Diagnosis, prevention, and treatment. Diabetes Care (2005) 28:164-76. doi: 10.2337/diacare.28.1.164

2. Magee C, Grieve DJ, Watson CJ, Brazil DP. Diabetic Nephropathy: a Tangled Web to Unweave. Cardiovasc Drugs Ther (2017) 31:579-92. doi: 10.1007/ s10557-017-6755-9

3. Thomas MC, Cooper ME, Zimmet P. Changing epidemiology of type 2 diabetes mellitus and associated chronic kidney disease. Nat Rev Nephrol (2016) 12:73-81. doi: 10.1038/nrneph.2015.173

4. Umanath K, Lewis JB. Update on Diabetic Nephropathy: Core Curriculum 2018. Am J Kidney Dis (2018) 71:884-95. doi: 10.1053/j.ajkd.2017.10.026

5. Braunwald E. Diabetes, heart failure, and renal dysfunction: The vicious circles. Prog Cardiovasc Dis (2019) 62:298-302. doi: 10.1016/ j.pcad.2019.07.003

6. Winocour PH. Diabetes and chronic kidney disease: an increasingly common multi-morbid disease in need of a paradigm shift in care. Diabetes Med (2018) 35:300-5. doi: 10.1111/dme.13564

7. Barrios C, Pascual J, Otero S, Soler MJ, Rodríguez E, Collado S, et al. Diabetic nephropathy is an independent factor associated to severe subclinical atheromatous disease. Atherosclerosis (2015) 242:37-44. doi: 10.1016/ j.atherosclerosis.2015.06.048

8. Zubiri I, Posada-Ayala M, Benito-Martin A, Maroto AS, Martin-Lorenzo M, Cannata-Ortiz $\mathrm{P}$, et al. Kidney tissue proteomics reveals regucalcin downregulation in response to diabetic nephropathy with reflection in urinary exosomes. Transl Res (2015) 166:474-84.e4. doi: 10.1016/ j.trsl.2015.05.007

9. Maric-Bilkan C. Sex Differences in Diabetic Kidney Disease. Mayo Clin Proc (2020) 95:587-99. doi: 10.1016/j.mayocp.2019.08.026

10. Cherney DZI, Sochett EB, Miller JA. Gender differences in renal responses to hyperglycemia and angiotensin-converting enzyme inhibition in diabetes. Kidney Int (2005) 68:1722-8. doi: 10.1111/j.1523-1755.2005.00588.x

\section{AUTHOR CONTRIBUTIONS}

Z-ZF and S-LL conceived the project, designed experiments. XG wrote the manuscript and analyzed data. H-HL collected the information and contributed to the writing of this manuscript. $\mathrm{XL}$ and $\mathrm{X}-\mathrm{HQ}$ contributed to the data interpretation. $\mathrm{RH}$ collect the information and contributed to the data interpretation and wrote the manuscript and analyzed data. All authors edited the final version of the manuscript. All authors contributed to the article and approved the submitted version.

\section{FUNDING}

This work was supported by the National Key Research and Development Program of China (2019YFA0802302, 2019YFA0802300), Special Fund of State Key Joint Laboratory of Environment Simulation and Pollution Control. The funders had no role in study design, data collection and analysis, decision to publish, or preparation of the manuscript.

\section{ACKNOWLEDGMENTS}

The authors thank all doctors, nurses and research staff at the Liaoning Medical University in Jinzhou, for their participation in this study.

11. Allen J, Davey HM, Broadhurst D, Heald JK, Rowland JJ, Oliver SG, et al. High-throughput classification of yeast mutants for functional genomics using metabolic footprinting. Nat Biotechnol (2003) 21:692-6. doi: 10.1038/nbt823

12. Zhang X, Zhang Y, Wang P, Zhang S-Y, Dong Y, Zeng G, et al. Adipocyte Hypoxia-Inducible Factor $2 \alpha$ Suppresses Atherosclerosis by Promoting Adipose Ceramide Catabolism. Cell Metab (2019) 30:937-51.e5. doi: 10.1016/j.cmet.2019.09.016

13. Sun L, Xie C, Wang G, Wu Y, Wu Q, Wang X, et al. Gut microbiota and intestinal FXR mediate the clinical benefits of metformin. Nat Med (2018) 24:1919-29. doi: 10.1038/s41591-018-0222-4

14. Qi X, Yun C, Sun L, Xia J, Wu Q, Wang Y, et al. Gut microbiota-bile acidinterleukin-22 axis orchestrates polycystic ovary syndrome. Nat Med (2019) 25:1225-33. doi: 10.1038/s41591-019-0509-0

15. Newgard CB. Interplay between lipids and branched-chain amino acids in development of insulin resistance. Cell Metab (2013) 15:606-14. doi: 10.1016/ j.cmet.2012.01.024.Interplay

16. Yang J, Chi Y, Burkhardt BR, Guan Y, Wolf BA. Leucine metabolism in regulation of insulin secretion from pancreatic beta cells. Nutr Rev (2010) 68:270-9. doi: 10.1111/j.1753-4887.2010.00282.x

17. Pedroso JAB, Zampieri TT, Donato J. Reviewing the effects of 1-leucine supplementation in the regulation of food intake, energy balance, and glucose homeostasis. Nutrients (2015) 7:3914-37. doi: 10.3390/nu7053914

18. Neinast M, Murashige D, Arany Z. Branched Chain Amino Acids. Annu Rev Physiol (2019) 10(81):139-64. doi: 10.1146/annurev-physiol-020518-114455

19. Chen K-H, Chen Y-L, Tang H-Y, Hung C-C, Yen T-H, Cheng M-L, et al. Dietary Leucine Supplement Ameliorates Hepatic Steatosis and Diabetic Nephropathy in db/db Mice. Int J Mol Sci (2018) 19(7):1921. doi: 10.3390/ ijms19071921

20. Mi N, Zhang XJ, Ding Y, Li GH, Wang WD, Xian HX, et al. Branched-chain amino acids attenuate early kidney injury in diabetic rats. Biochem Biophys Res Commun (2015) 466:240-6. doi: 10.1016/j.bbrc.2015.09.017

21. Macotela Y, Emanuelli B, Bång AM, Espinoza DO, Boucher J, Beebe K, et al. Dietary leucine - an environmental modifier of insulin resistance acting on 
multiple levels of metabolism. PloS One (2011) 6(6):e21187. doi: 10.1371/ journal.pone.0021187

22. Alberti KG, Zimmet PZ. Definition, diagnosis and classification of diabetes mellitus and its complications. Part 1: diagnosis and classification of diabetes mellitus provisional report of a WHO consultation. Diabetes Med (1998) 15:53953. doi: 10.1002/(SICI)1096-9136(199807)15:7<539::AID-DIA668>3.0.CO;2-S

23. Selby NM, Taal MW. An updated overview of diabetic nephropathy: Diagnosis, prognosis, treatment goals and latest guidelines. Diabetes Obes Metab (2020) 22:3-15. doi: 10.1111/dom.14007

24. Chen C, Lu FC. Department of Disease Control Ministry of Health, PR China. The guidelines for prevention and control of overweight and obesity in Chinese adults. Biomed Environ Sci (2004) 17 Suppl:1-36.

25. Desquilbet L, Mariotti F. Dose-response analyses using restricted cubic spline functions in public health research. Stat Med (2010) 29:1037-57. doi: 10.1002/ sim. 3841

26. Li J, Cao YF, Sun XY, Han L, Li SN, Gu WQ, et al. Plasma tyrosine and its interaction with low high-density lipoprotein cholesterol and the risk of type 2 diabetes mellitus in Chinese. J Diabetes Invest (2019) 10:491-8. doi: 10.1111/ jdi. 12898

27. Andersson T, Alfredsson L, Källberg H, Zdravkovic S, Ahlbom A. Calculating measures of biological interaction. Eur J Epidemiol (2005) 20:575-9. doi: $10.1007 / \mathrm{s} 10654-005-7835-\mathrm{x}$

28. Wang TJ, Larson MG, Vasan RS, Cheng S, Rhee EP, McCabe E, et al. Metabolite profiles and diabetes. Nat Med (2011) 17:448-53. doi: 10.1038/ nm.2307.Metabolite

29. Honda T, Kobayashi Y, Togashi K, Hasegawa H, Iwasa M, Taguchi O, et al. Associations among circulating branched-chain amino acids and tyrosine with muscle volume and glucose metabolism in individuals without diabetes. Nutrition (2016) 32:531-8. doi: 10.1016/j.nut.2015.11.003

30. Newgard CB, An J, Bain JR, Muehlbauer MJ, Stevens RD, Lien LF, et al. A branched-chain amino acid-related metabolic signature that differentiates obese and lean humans and contributes to insulin resistance. Cell Metab (2009) 9(4):311-26. doi: 10.1016/j.cmet.2009.02.002. Erratum in: Cell Metab (2009) 9(6):565-6.

31. Zhang J, Yan L, Chen W, Lin L, Song X, Yan X, et al. Metabonomics research of diabetic nephropathy and type 2 diabetes mellitus based on UPLC-oaTOF-MS system. Anal Chim Acta (2009) 650:16-22. doi: 10.1016/ j.aca.2009.02.027

32. Saleem T, Dahpy M, Ezzat G, Abdelrahman G, Abdel-Aziz E, Farghaly R. The Profile of Plasma Free Amino Acids in Type 2 Diabetes Mellitus with Insulin Resistance: Association with Microalbuminuria and Macroalbuminuria. Appl Biochem Biotechnol (2019) 188:854-67. doi: 10.1007/s12010-019-02956-9

33. Welsh P, Rankin N, Li Q, Mark PB, Würtz P, Ala-Korpela M, et al. Circulating amino acids and the risk of macrovascular, microvascular and mortality outcomes in individuals with type 2 diabetes: results from the ADVANCE trial. Diabetologia (2018) 61:1581-91. doi: 10.1007/s00125-018-4619-x

34. Amaral AG, Rafacho A, MacHado De Oliveira CA, Batista TM, Ribeiro RA, Latorraca $\mathrm{MQ}$, et al. Leucine supplementation augments insulin secretion in pancreatic islets of malnourished mice. Pancreas (2010) 39:847-55. doi: 10.1097/MPA.0b013e3181d37210

35. Xu G, Kwon G, Cruz WS, Marshall CA, McDaniel ML. Metabolic regulation by leucine of translation initiation through the mTOR-signaling pathway by pancreatic $\beta$-cells. Diabetes (2001) 50:353-60. doi: 10.2337/ diabetes.50.2.353

36. Yang J, Dolinger M, Ritaccio G, Mazurkiewicz J, Conti D, Zhu X, et al. Leucine Stimulates Insulin Secretion via Down-regulation of Surface Expression of Adrenergic 2A Receptor through the mTOR (Mammalian Target of Rapamycin) Pathway. J Biol Chem (2012) 287:24795-806. doi: 10.1074/ jbc.M112.344259

37. Filiputti E, Rafacho A, Araújo EP, Silveira LR, Trevisan A, Batista TM, et al. Augmentation of insulin secretion by leucine supplementation in malnourished rats: possible involvement of the phosphatidylinositol 3phosphate kinase/mammalian target protein of rapamycin pathway. Metabolism (2010) 59:635-44. doi: 10.1016/j.metabol.2009.09.007

38. Efeyan A, Zoncu R, Sabatini DM. Amino acids and mTORC1: from lysosomes to disease. Trends Mol Med (2013) 18:524-33. doi: 10.1016/j.molmed.2012. 05.007

39. Lee MJ, Feliers D, Mariappan MM, Sataranatarajan K, Mahimainathan L, Musi N, et al. A role for AMP-activated protein kinase in diabetes-induced renal hypertrophy. Am J Physiol Renal Physiol (2007) 292(2):F617-27. doi: 10.1152/ajprenal.00278.2006

40. Phillips SM, Atkinson SA, Tarnopolsky MA, MacDougall JD. Gender differences in leucine kinetics and nitrogen balance in endurance athletes. J Appl Physiol (1993) 75:2134-41. doi: 10.1152/jappl.1993.75.5.2134

41. López N, Sánchez J, Palou A, Serra F. Gender-associated impact of early leucine supplementation on adult predisposition to obesity in rats. Nutrients (2018) 10(1):76. doi: 10.3390/nu10010076

Conflict of Interest: The authors declare that the research was conducted in the absence of any commercial or financial relationships that could be construed as a potential conflict of interest.

Copyright $\odot 2021 \mathrm{Gao}, \mathrm{Hou}, \mathrm{Li}$, Qiu, Luo, Liu and Fang. This is an open-access article distributed under the terms of the Creative Commons Attribution License (CC BY). The use, distribution or reproduction in other forums is permitted, provided the original author(s) and the copyright owner(s) are credited and that the original publication in this journal is cited, in accordance with accepted academic practice. No use, distribution or reproduction is permitted which does not comply with these terms. 